\title{
Effectiveness of Mifepristone in the Treatment of Uterine Leiomyomata
}

\author{
Sinha M, ${ }^{1}$ Kyal A, ${ }^{1}$ Mukhopadhay $\mathbf{P}^{1}$ \\ ${ }^{1}$ Department of Obstetrics and Gynaecology, Medical College and Hospital, Kolkata, India.
}

\begin{abstract}
Aims: The goal of this study was to determine the effects of mifepristone in perimenopausal women with leiomyomas, thereby to see a decrease in severity of symptoms and a decrease in size of the leiomyomas.

Methods: This was a prospective study conducted at Eden HospitalMedical College and Hospital, Kolkatafrom July 2010 to June 2011. Fifty patients received $20-25 \mathrm{mg}$ mifepristone daily and comparison was made between pre and post treatment symptoms and leiomyoma volume.
\end{abstract}

Results: All patients became amenorrhoeic after treatment, relieving heavy menstrual flow most complained of. Lower abdominal pain improved by $>80 \%$ in most patients and volume of leiomyoma decreased appreciably. The drug did not have any major side effects. Endometrial hyperplasia detected by ultrasound in $42 \%$ patients was only of simple type on biopsy.

Conclusions: Mifepristone can be useful in treating symptomatic women with uterine leiomyoma in perimenopausal age group, in those awaiting surgery to stop bleeding and improve anaemia and to reduce size of tumor to make surgery technically easier, making it a cheaper alternative to GnRH agonists and without any major side effects.

Keywords: fibroid, mifepristone, volume of fibroid, leiomyoma.

\section{INTRODUCTION}

Uterine leiomyomata or fibroids are common benign pelvic tumours and account for up to $40 \%$ of all hysterectomies. ${ }^{1}$ Recent studies have shown the effectiveness of various modes of medical management for the treatment of uterine leiomyomas. The most widely used medical therapy is GnRH agonists, which have antiestrogenic side effects and so cannot be used on a long term basis. Amongst the other drugs studied, anti-progesterone mifepristone is the most promising. Surgery and treatment with GnRH agonists have their own complications and are not always feasible. . $^{2,3}$

\section{CORRESPONDENCE}

Dr Mayurika Sinha

Department of Obstetrics and Gynaecology,

Medical College and Hospital, Kolkata, India.

Email: mayu doc004@yahoo.com

Phone: $9198 \overline{3} 0867044$
Studies have suggested that leiomyomas growth is steroiddependent and that mitotic activity in leiomyomas is greatest in the luteal phase. ${ }^{4}$ Recent studies have provided further biochemical, histological and clinical evidence that progesterone has a critical role in leiomyoma growth. Recently mifepristone, a progesterone receptor modulator with primarily antagonistic properties has been shown to decrease leiomyoma size..$^{5-7}$

Westudied the effects of mifepristone treatment on leiomyomas, specifically on the size of the leiomyoma and decrease in associated symptoms like pain and menorrhagia.

The papers in this journal are published under the terms of the Creative Commons Attribution License. Users are allowed to read download, copy, distribute, print, search, or link to the full texts of the articles in this journal without asking prior permission from the publisher or the author. 


\section{METHODS}

The study was conducted at Eden Hospital,Medical College and Hospital, Kolkata for a period of one year, commencing from July 2010 to June 2011. This study compared pre and post treatment leiomyoma volume and symptoms.

First ultrasound at the initiation of treatment noting the size and volume of fibroid and the endometrial thickness was done in all patients. Second ultrasound was done after three months of treatment with mifepristone recording the amount of decrease in fibroid volume and increase in endometrial thickness.

Patients with symptomatic uterine leiomyomas in premenopausal age without endometrial hyperplasia were included in the study.Women with systemic health problems like severe anemia and acute symptoms and those who used hormonal medication within threemonths of treatment initiation were excluded from the study.

In this study 50 patients with symptomatic leiomyomas were treated with $20-25 \mathrm{mg}$ mifepristone daily for three months to note clinical improvement in symptoms and radiological decrease in fibroid volume. After this time period improvement in menorrhagia and pain lower abdomen were noted. Also recorded were the initial ultrasound volume of the fibroid and reduction in volume after three months of treatment. Development of untoward effects of mifepristone was also noted, namely endometrial hyperplasia. The information accumulated by treating 50 patients with mifepristone was then plotted in tables and charts for the ease of statistical analysis. Finally all the data was analysed to determine whether mifepristone caused any significant improvement in symptoms of patients or significant reduction in the volume of leiomyoma radiologically. McNemar Chi Square Test and Wilcoxon Signed Rank Analysis to determine the significance level of the study was done.

\section{RESULTS}

The commonest presenting symptoms of the patients were menorrhagia and pain lower abdomen. Though more than half of the patients had small fibroids with volumes $<100$ $\mathrm{cm}^{3}, 22 \%$ had quite large ones some even measuring $>500$ $\mathrm{cm}^{3}$.

The study showed $100 \%$ improvement of menorrhagia as all the 34 patients with heavy bleeding were rendered amenorrhoeic during three months of treatment with mifepristone.

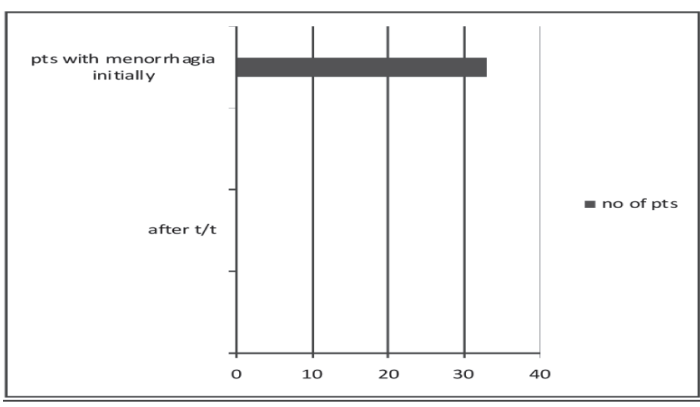

Figure 1. Bar diagram showing $100 \%$ improvement in menorrhagia in 34 patients presenting with excessive bleeding after 3 months of treatment with mifepristone.

Table 1 shows percentage of pain relief amongst the patients as determined by the pain analog score after three months of mifepristone use. Ninety percent of the patients reported reduction in pain of more than $40 \%$ and $67.9 \%$ had more than $80 \%$ decrease in pain.

Table 1. Improvement in pain lower abdomen or dysmenorrhoea $(n=27)$.

\begin{tabular}{lll}
\hline $\begin{array}{l}\text { Amount of pain } \\
\text { reduction after } \\
\text { mifepristone }\end{array}$ & $\begin{array}{l}\text { Number of } \\
\text { patients }\end{array}$ & Percent \\
\hline $0-20 \%$ & 0 & $0 \%$ \\
$21-40 \%$ & 3 & $10.7 \%$ \\
$41-60 \%$ & 4 & $14.3 \%$ \\
$61-80 \%$ & 2 & $7.1 \%$ \\
$81-100 \%$ & 18 & $67.9 \%$ \\
\hline
\end{tabular}

Table 2 shows the percentage of reduction in leiomyoma volume after treatment as compared to the original volume. Almost $66 \%$ patients showed more than $80 \%$ reduction in fibroid volume as per ultrasound images.

Table 2. Reduction in the volume of leiomyoma $(n=47)$.

\begin{tabular}{lll}
\hline $\begin{array}{l}\text { Reduction in } \\
\text { volume after } \\
\text { mifepristone }\end{array}$ & Patients & Percent \\
\hline $0-20 \%$ & 3 & $6.4 \%$ \\
$21-40 \%$ & 3 & $6.4 \%$ \\
$41-60 \%$ & 5 & $10.6 \%$ \\
$61-80 \%$ & 5 & $10.6 \%$ \\
$81-100 \%$ & 31 & $65.9 \%$ \\
\hline
\end{tabular}

Table 3 deals with the side effects of mifepristone, $42 \%$ of the patients showed endometrial hyperplasia ( $>8$ $\mathrm{mm}$ endometrial thickness). All patients of hyperplasia underwent biopsy and the histopathology showed simple hyperplasia. 
Table 3. Patients with endometrial hyperplasia after 3 months of mifepristone $(n=50)$.

\begin{tabular}{lll}
\hline $\begin{array}{l}\text { Endometrial } \\
\text { thickness }\end{array}$ & No of patients & \% of patients \\
\hline$<$ or $=8 \mathrm{~mm}$ & 29 & $58 \%$ \\
$>8 \mathrm{~mm}$ & 21 & $42 \%$ \\
\hline
\end{tabular}

\section{DISCUSSION}

Mifepristone is effective in decreasing the severity of symptoms of leiomyoma and decreasing the volume of tumor. The present study also determined the effectiveness of this drug in treating uterine leiomyoma and compares the result to those obtained previously. The presenting symptoms of our patients were variable with $40 \%$ presented with only menorrhagia, $26 \%$ with lower abdominal pain and $28 \%$ complained of both heavy bleeding and pain. Overall $68 \%$ presented with increased bleeding per vagina, corroborating the fact that abnormal bleeding is the commonest symptom of leiomyomas.

There was a huge improvement in this symptom as all 34 patients with menorrhagia became amenorrhoeic after 3 months of treatment with mifepristone. Pallor improved and the patients felt a sense of well- being. They were counselled about this effect of mifepristone and were assured that their menstrual function would resume after stoppage of treatment.The finding of $100 \%$ amenorrhea in this study corroborates with all previous studies ${ }^{8,9}$ using mifepristone $>$ or $=20 \mathrm{mg}$ daily.

The patients were initially asked to rate the amount of pain they felt on a scale of 1 to 10 (pain analog score) and the procedure was repeated after three months of treatment and $68 \%$ of the patients reported a subjective improvement of $81-100 \%$ by this scoring system and $94 \%$ recorded some amount of improvement.

Table 4. Comparison with various other studies.

\begin{tabular}{lll}
\hline First Author & $\begin{array}{l}\text { Mifepristone } \\
\text { Dose }(\mathrm{mg})\end{array}$ & $\begin{array}{l}\text { \% of reduction } \\
\text { in volume of } \\
\text { fibroid }\end{array}$ \\
\hline Murphy $^{10}$ & 50 & $49+/-9$ \\
Murphy $^{11}$ & 25 & $56+/-5$ \\
Reinsch $^{12}$ & 25 & 32 \\
Yang $^{8}$ & 20 & 33 \\
Zeng $^{9}$ & 12.5 & 74 \\
Engman $^{13}$ & 25 & 28 \\
Present Study & 25 & 80 \\
\hline
\end{tabular}

The most important objective criteria to prove the efficacy of this drug was ultrasonographic reduction in tumour volume. Initially the volume was calculated using the formula $4 / 3 \pi a b c$, where $a, b$ and $c$ are the diameters of the fibroid in three dimensions. After three months of treatment volume was recalculated and reduction in volume was noted. Ninty-four percent of patients showed some reduction in the volume of leiomyoma with $66 \%$ patients showing a reduction of $81-100 \%$. Other studies ${ }^{10-}$ ${ }^{12}$ have also shown reduction in fibroid volume by up to $87 \%$. A statistical analysis of this data by Wilcoxon Signed rank Test showed a $p$ value of $<0.001$. Only 3 of the 50 patients showed radiological increase in the volume of leiomyoma. Of them two underwent hysterectomy later in which the gross specimen did not show any evidence of the presence of leiomyoma, but both had large adenomyoticuteri. The mean $\%$ of reduction in volume was $80 \%$ (Table 4 ), which is much higher than previous ones, but almost corresponds to the study by Zeng. ${ }^{8}$

Total $42 \%$ of the patients (Table 3 ) developed endometrial hyperplasia according to the ultrasound report, with endometrial thickness $>8 \mathrm{~mm}$. Previous studies ${ }^{12,13}$ have also showed this effect, with the number of patients developing endometrial hyperplasia increasing as the dose of mifepristone was increased from 5 to $25 \mathrm{mg}$ daily. All the patients were biopsied and the histopathology report showed simple hyperplasia only.

Though this study had some methodological disadvantages, i.e., small sample size, non-randomized and without any control arm like treatment with $\mathrm{GnRH}$ agonist, but it definitely showed that mifepristone causes both clinical and radiological improvement for uterine leiomyomas.

\section{CONCLUSIONS}

Mifepristone can be useful in treating symptomatic women with uterine leiomyoma in the perimenopausal age group, in patients with menorrhagia awaiting surgery to improve anemia, and to reduce the size of tumors to make the surgery technically easier.

Additionally this drug is cheaper than GnRH agonists. So it definitely shows promise of emerging as an alternative medical therapy for perimenopausal women and women with menorrhagia and pallor waiting for surgical intervention. Whether it can be used for all patients on a long term basis and the probability of recurrence of fibroids after stopping the drug needs to be evaluated further with larger randomized controlled trials. 


\section{REFERENCES}

1. Cramer SF, Patel A. The frequency of uterine leiomyomas Am J ClinPathol. 1990;94:435-8.

2. OlufowobiO, Sharif K, Pappaionou S. Are the anticipated benefits of myomectomy achieved in women of reproductive age? A 5-year review of the results at a UK tertiary hospital. J Obstet Gynecol. 2004;24:434-40.

3. Upopadhyaya NP, Doody MC, Googe PB. Histopathologica changes in leiomyoma treated with leuprolide acetate. Fertil Steril. 1990;54:811-4.

4. Tiltman AJ. The effect of progestins on the mitotic activity of uterine fibromyomas. Int J Gynecol Pathol. 1985;21:32-41.

5. Kawaguchi K, Fujji S, Konishi I. Mitotic activity in the uterine leiomyomas during the menstrual cycle. Am J Obstet Gynecol. 1989;160:637-41.

6. Shimomura $\mathrm{Y}$, Matsuo $\mathrm{H}$, Samoto $\mathrm{T}$. Up regulation by progesterone of proliferating cell nuclear antigen and epidermal growth factor expression in human uterine leiomyoma. J Clin Endocrinol Metab. 1998;83:2192-8.

7. Cramer SF, Robertson AL, Ziats NP. Growth potential of human uterine leiomyomas: some in vitro observations and their implications. Obstet Gynecol. 1985;66:36-41.
8. Yang H, Zen S, Li K. Treatment of uterine leiomyoma by two different doses of mifepristone [ in Chinese]. Zhongua $\mathrm{Fu}$ Chan KeZhaZi. 1996;31:624-6.

9. Zeng $C, G u$ M, Huang $H$. A clinical control study on the treatment of uterine leiomyoma with $\mathrm{GnRH}$ agonist or mifepristone[ in Chinese]. Zhonghua Fu Chan KeZaZhi. 1998;33:490-2.

10. Murphy AA, Kettel LM, Morales AJ, Roberts VJ, Yen SS.. Regression of uterine leiomyomata in response to the anti progesterone RU 486. J Clin Endocrinol Metab. 1993;76(2):513-7

11. Murphy AA, Morales AJ, Kettel LM, Roberts VJ, Yen SS. Regression of uterine leiomyomatato the anti progesterone RU 486: dose-response effect. Fertil Steril. 1995:64:187-90.

12. Reinsch RC, Murphy AA, Morales AJ, Yen SS. The effects of RU486 and leuprolide acetate on uterine blood flow in the fibroid uterus: a prospective randomized study. Am J Obstet Gynecol. 1994;170:1623-7.

13. Engman $M$, Granberg $S$, William $A R$, Meng $C X$, Lalitkumar PG, Gemzell-Danielson K. Mifepristone for treatment of uterine leiomyoma: a prospective randomized placebo controlled trial. Hum Reprod. 2009 Aug;24(8):1870-9. 